\title{
LEITURA LITERÁRIA INFANTIL E O PAPEL DO BIBLIOTECÁRIO MEDIADOR
}

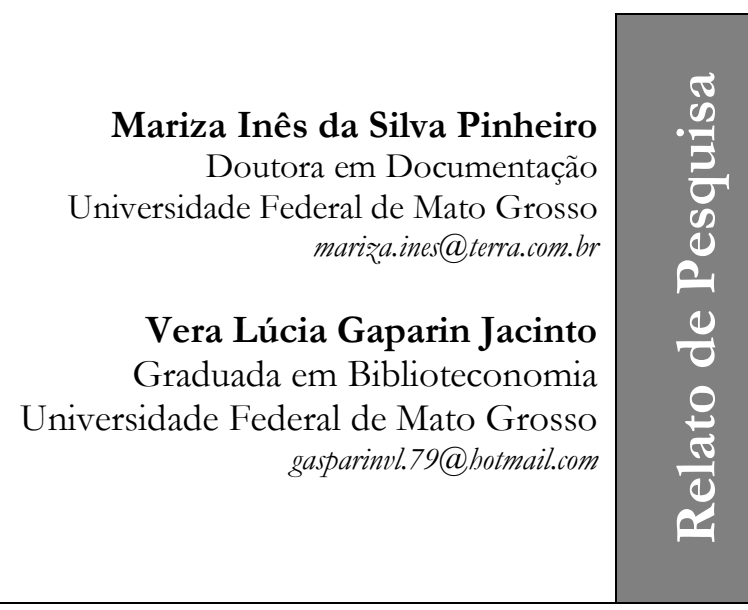

\section{Resumo}

Tendo por objeto de estudo as histórias infantis do acervo da Biblioteca da "Escola Estadual Professora Renilda Silva Moraes" da cidade de Rondonópolis - MT a pesquisa buscou identificar a moral e a narrativa das histórias e verificar se as literaturas são lidas pela bibliotecária antes de sua disponibilização. Foram analisadas 100 obras escolhidas aleatoriamente no acervo no período de abril a junho de 2015 e teve dois indicadores para análise: o nível de compreensão e a moral da história. Os resultados mostram que que o nível de compreensão das histórias foi de fácil entendimento, que todas as obras apresentam uma moral explícita ou implícita, demonstrando algumas mensagens de amor, amizade e respeito à natureza e que a bibliotecária lê as obras no momento do tombamento das literaturas. Considera-se que dar às crianças a oportunidade de conhecer uma obra literária pode contribuir para a construção do seu gosto pela leitura. Conclui-se que tão importante quanto, saber se uma obra infantil apresenta, ou não, uma "moral da história" é reafirmação da ideia de que os livros são um bom caminho para ampliar o universo cultural dos futuros leitores, oportunizando entrar em contato com situações desconhecidas e/ou diferentes.

Palavras-chave

Literatura infantil. Moral da história. Leitura literária. Bibliotecário mediador.

\section{INTRODUÇÃO}

A literatura infantil faz parte dos acervos de toda biblioteca infantil, escolar e pública com uma diversidade de títulos dos mais variados gêneros literários. Todavia, infelizmente, muitos destes acervos ficam isolados em bibliotecas fechadas e alunos sem acesso.

Assim, a partir de algumas leituras e sobre a vivência nas bibliotecas escolares, surgiu o tema desta pesquisa com o objetivo principal de identificar como ocorre o incentivo da leitura para as crianças, desde os primeiros dias de aula. Os objetivos específicos são: verificar se existe diálogo com as crianças sobre a história contada nos livros de literaturas infantis e se elas também leem as literaturas infantis antes de disponibilizarem na estante.

Portanto, para atingir os objetivos propostos foi realizada uma entrevista semiestruturada com a bibliotecária responsável da Biblioteca da Escola Estadual Professora Renilda Silva Moraes, na cidade de Rondonópolis-MT.

Ao chegar a idade escolar a criança tem o direito de frequentar uma biblioteca infantil, pública ou escolar. Neste contexto, é importante que ela comece a ter acesso a um grande número de obras literárias e é neste momento que o bibliotecário deve desenvolver na criança o prazer de utilizar esse espaço escolar com atividades que possam proporcionar o gosto pela leitura literária infantil. É necessário, porém, que esse 
profissional tenha um perfil inovador, proativo, dinâmico, atencioso e goste de ler.

Desse modo, torna-se muito melhor e mais fácil interagir com os professores e pais, participar das reuniões pedagógicas e estudar sobre o processo educacional para conhecer e desenvolver projetos em prol do gosto pela leitura.

O texto literário é um bom início para despertar o gosto pela leitura dos pequenos estudantes. Nesse sentido, são estudados, ainda, alguns temas: leitura literária infantil, biblioteca escolar e uma breve apresentação do campo da pesquisa a Biblioteca Escola Estadual Professora Renilda Silva Moraes, localizada na cidade de Rondonópolis-MT. Cabe, ainda, destacar um assunto relevante nesta discussão, a união do bibliotecário, educadores e os pais na formação de valores e incentivo à leitura literária.

\section{LEITURA LITERÁRIA INFANTIL}

A leitura é fundamental para o desenvolvimento individual e social, por isso, investir em meios que motivem a criança a gostar de ler é um grande passo inicial no processo educacional.

O incentivo à leitura deveria começar nos primeiros anos de vida de uma criança através da família e, depois, nas séries iniciais com a literatura infantil na escola. No entanto, sabe-se que atualmente é um grande desafio para os educadores (pais, professores e bibliotecário) proporcionar momentos de leitura às crianças e jovens, porque as escolas nem sempre possuem uma biblioteca e, as que a têm não apresentam um profissional comprometido com a leitura de forma convidativa.

De acordo com Santos (2014, p. 31), estimular a leitura na escola, principalmente entre leitores jovens, é um trabalho que só pode ser feito com uma abordagem textual direcionada para a participação e interpretação crítica do leitor - o que é possível se cada obra for analisada conforme suas peculiaridades. $O$ professor deve motivar, portanto, a cumplicidade gerada na interação leitor-texto e a participação ativa do aluno, proporcionando-lhe a oportunidade de trilhar um caminho particular na leitura.

A literatura infantil é um excelente instrumento de mediação que o bibliotecário e o professor podem trabalhar no processo do conhecimento de várias áreas do saber. Assim, para Cagneti (1996, p. 7):

A literatura infantil é, antes de tudo, arte: fenômeno de criatividade que representa o mundo, o homem, a vida, através da palavra. Funde os sonhos e a vida prática; o imaginário e o real; os ideais e sua possível/impossível realização.

A expressão infantil refere-se à infância, às crianças, então, literatura infantil seria a arte da literatura destinada às crianças. Sobre esse assunto Cademartori $(2010)^{1}$ define que a literatura infantil é:
Um gênero literário definido pelo público a que se destina. Certos textos são considerados pelos adultos como sendo próprios à leitura pela criança e é, a partir desse juízo, que recebem a definição de gênero e passam a ocupar determinado lugar entre os demais livros. Portanto, o que é classificado como literatura infantil não independe da concepção que a sociedade tem da criança e de seu entendimento do que seja infância.

As histórias lidas, contadas ou mediadas nos conduzem a diferentes mundos, alguns com mistérios e surpresas, poéticos e românticos e encantamentos que fazem a nossa imaginação desprender-se da realidade, porém, sempre muito interessante e curioso, que diverte e ensina.

Conforme nos coloca Colomer (2007, p. 31):

[...] o objetivo da formação literária é, em primeiro lugar, o de contribuir para formação da

${ }^{1}$ Disponível em:

http://ceale.fae.ufmg.br/app/webroot/glossarioceale /verbetes/literatura-infantil 
pessoa, uma formação que aparece ligada indissoluvelmente à construção da sociabilidade e realizada através da confrontação com textos que explicitam a forma em que a gerações anteriores e as contemporâneas abordaram a avaliação da atividade humana através da linguagem.

A literatura diverte e ensina como mencionam Cagneti (1996), Carvalho (1989) e Coelho (2000), então é necessário que a leitura consiga estabelecer um vínculo entre a criança e a literatura infantil para instruir, educar e "viajar" rumo à aprendizagem.

\subsection{Moral da história infantil}

A sociedade veio para organizar a convivência entre o homem e a organização que é composta por regras e normas que garantem, a cada indivíduo, direitos e valores que deverão ser compreendidos desde seu nascimento. Dentro desta "organização" está à formação moral do ser humano, que vem de princípios aprendidos no decorrer de sua vida e são essenciais para formação de seu caráter.

O termo moral é definido pelo dicionário eletrônico Aurélio, como "conjunto de princípios e valores morais de conduta do homem". Sendo assim, moral da história refere-se a esses princípios e valores morais de conduta, presentes em seu enredo. Para Mallmann (2011, p. 10, os valores morais.

se apresentam nas histórias de forma muito sutil, porém podem ser trabalhados dentro da biblioteca, utilizando a literatura infantil, e buscando refletir e opinar através da conduta e comportamento dos personagens é possível construir um novo olhar para a sociedade, a partir do resgate dos valores morais tais como: a solidariedade, autonomia, respeito ao próximo e respeito a natureza.
Segundo Piaget (1994, p 23,) o desenvolvimento da moral abrange três fases, que são descritas como:

- $\mathbf{1}^{\mathbf{a}}$ - anomia (crianças até 5 anos): geralmente a moral não se coloca, com as normas de conduta sendo determinadas pelas necessidades básicas. Porém, quando as regras são obedecidas, são seguidas pelo hábito e não por uma consciência do que se é certo ou errado. Um bebê que chora até que seja alimentado é um exemplo dessa fase.

- $\mathbf{2}^{\mathbf{a}}$ - heteronomia (crianças até 9,10 anos de idade): $O$ certo é o cumprimento da regra e qualquer interpretação diferente desta não corresponde a uma atitude correta. Um homem pobre que roubou um remédio da farmácia para salvar a vida de sua esposa está tão errado quanto um outro que assassinou a esposa, seguindo o raciocínio heteronômico.

- $3^{\text {a }}$ - autonomia: legitimação das regras. $\mathrm{O}$ respeito às regras é gerado por meio de acordos mútuos. Sendo esta a última fase do desenvolvimento da moral.

Nessa perspectiva, Piaget (1994) menciona que a responsabilidade pelos atos de uma pessoa é avaliada de acordo com as consequências desses atos e não pela sua intenção. $\mathrm{O}$ ser humano obedece às normas por medo da punição. $\mathrm{Na}$ ausência da autoridade ocorre a desordem e a indisciplina. Esse pensamento faz sentido, pois, observa-se no sistema legal positivado, que todos os atos geram consequências e quando essas trazem prejuízos, ocorre à punição.

Entretanto, o que é moral da história para Miranda (2015, p. 4)* A moral da história é "uma lição que se pode tirar de uma história...É a conclusão a que cada um de nós chega ao conhecê-la. E que pode muito bem ser diferente da conclusão de uma outra pessoa a respeito do mesmo assunto."

$\mathrm{O}$ autor ainda menciona que:

${ }^{*}$ Livro eletrônico 
A moral da história, dito de outro modo, refere-se de sua percepção do que the foi contado e que pode ser uma história verdadeira ou inventada. Chamo de verdadeira a história que aconteceu de fato e de inventada aquela que corresponde a uma fábula proposta pelo autor, a partir de sua compreensão da realidade [...]. A moral de uma história, em suma, prova-nos que a leitura é uma fonte inesgotável de conhecimento da vida e do mundo, pois suas lições aplicam-se ao dia a dia, onde dependendo da situação, recordamos da mensagem final de certa história que ouvimos (ou lemos) e agimos conforme a conclusão que ela nos inspirou. Moral da história: a literatura e a leitura estão a serviço da vida das pessoas. E o próprio ato de ler revela quais são as melhores leituras para você. (MIRANDA, 2005, p. 7).

Diante do exposto, entende-se que uma obra literária pode ter uma moral da história que nem sempre está explícita. A moral da história pode estar nas entrelinhas (implícita), para fazer o leitor pensar e interpretar, talvez dentro de seu conhecimento de mundo, para entender a mensagem da história.

Nesse sentido, em um livro infantil, acredita- se que o autor tenha a intenção de apresentar uma moral da história explícita, quer dizer que, o público infantil, após a leitura da obra literária, aprender-se-á algum ensinamento, com isso, a moral da história vivenciada no enredo da obra, apresentados através dos personagens da obra literária.

\section{BIBLIOTECA ESCOLAR}

A biblioteca escolar é considerada um local de fontes informacionais imprescindíveis de apoio ao ensino e aprendizado e, sobretudo, um meio motivacional para a leitura, que as instituições de ensino possuem ou deveriam possuir. Não funciona apenas como um centro de pesquisa, mas, também, como um local de interação e desenvolvimento crítico dos discentes em fase de desenvolvimento cognitivo.

Para Durban Roca (2012, p. 26), a biblioteca escolar não é um "centro de recursos a serviço da aprendizagem", mas um "contexto de aprendizagem onde, graças à interação com determinados recursos, processos de ensino e aprendizagem e práticas de leitura são facilitados".

Sendo assim, pode ser considerada como um espaço pedagógico que complementa as atividades no processo de ensino e aprendizagem. Nessa visão, as atividades de incentivo à leitura são fundamentais para essa complementação da vida escolar do aluno.

Diante disso, Caldin (2003, p. 54) menciona que, a biblioteca escolar: "[...] é o local por excelência para apresentar a leitura como uma atividade natural e prazerosa, posto que, para muitas crianças, configura-se como a única oportunidade de ter acesso aos livros que não são didáticos."

Pesquisas comprovam que, ainda, faltam bibliotecas e bibliotecários nas instituições públicas e privadas de educação em nosso país. Essa realidade faz dificultar a intenção de estimular a leitura às crianças.

Vale ressaltar que existe a Lei $\mathrm{n}^{\circ}$ 12.244 de 24 de maio de 2010 prevê a instalação de bibliotecas escolares em todas as unidades de ensino do país, sejam elas públicas ou privadas, respeitadas as diretrizes para o uso destas bibliotecas. A Lei também prevê a contratação de bibliotecários para gerir as mesmas, sendo que isto deve ocorrer até o ano de 2020 (BRASIL, 2010).

A aplicação desta Lei deverá trazer grandes benefícios à população, possibilitando maior acesso ao conhecimento e à leitura, como forma de ajudar na formação da cidadania de leitores brasileiros. Assim, trabalhar em uma biblioteca escolar tem-se a possibilidade de conviver diretamente com crianças e/ou adolescentes o tempo todo. E para que a biblioteca possa ser frequentada, esse profissional deve oferecer serviços adequados ao perfil de seus usuários, um ambiente aconchegante e prazeroso e, principalmente, para que os frequentadores 
se sintam estimulados à leitura através das obras bibliográficas existentes no acervo, bem como às disponíveis nas bibliotecas virtuais/eletrônicas.

Nos dias atuais, a biblioteca, mesmo com as novas tecnologias, não perdeu o seu significado constituído pela história.

[...] Muitos dos seus atributos tradicionalmente conhecidos ainda são responsáveis pela visão da biblioteca que temos. $O$ que a mantém viva e atuante é a sua essência. Seja com rolos de papiros ou com um microprocessador fabricado com silício, seja tateando entre as estantes à procura de um livro ou utilizando um catálogo automatizado, com documentos de conteúdo religioso ou com um artigo dos mais recentes periódicos sobre tecnologia; a biblioteca continua sendo valorizada e reconhecida pelo seu papel que exerce no processamento e na disseminação da informação e do conhecimento (MORIGI; SOUTO, 2005, p. 197).

De igual modo, Moro e Estabel (2011, p. 68) destaca que "a biblioteca escolar é o espaço democrático de formação da cidadania, que propicia o acesso e o uso da informação e auxilia na constituição de um sujeito agente na sociedade em que vive."

\subsection{O bibliotecário escolar como mediador no incentivo à leitura literária}

O bibliotecário escolar é um mediador da informação, portanto, desempenha um papel de grande valor na biblioteca escolar. Cabe-lhe algumas funções como as normas de funcionamento, a formação e desenvolvimento da coleção, o tratamento e disseminação da informação, iniciação à pesquisa e, a principal, as ações motivadoras para o gosto pela leitura. Deste modo, toda comunidade escolar e a família será privilegiada com a contribuição do bibliotecário.
A presença desse profissional nos serviços inerentes à biblioteca escolar faz necessário no fomento e formação de leitores, juntamente com os professores e os pais.

Para a existência de uma biblioteca com condições de atender ao público visando desenvolver a leitura é necessário que três elementos básicos estejam interligados entre si: bibliotecários, livros e usuários. Sob esta questão Silva (1997, p.106) comenta que:

Sem o bibliotecário, com os seus conhecimentos organizacionais $\mathrm{e}$ de orientação, o espaço dos livros torna-se altamente caótico e tende a perecer rapidamente. Sem livros, o espaço torna-se inútil. Sem usuário, o espaço da biblioteca não se dinamiza, perde o seu valor e morre.

O bibliotecário escolar, "conquanto raramente presente nas escolas, é o profissional qualificado, responsável pelo planejamento e gestão da biblioteca escolar" (IFLA/UNESCO, 2005). Somando-se a isso, o bibliotecário é também um mediador da leitura e da informação entre o aluno/professor/pais, dando suporte à pesquisa, na leitura e em atividades de lazer. Para ser um incentivador de leitura, é preciso conhecer algumas formas que contribuem para que o aluno se sinta motivado a ler como, por exemplo, através de projetos, tais como: hora do conto, teatro, fantoches, desenhos, pinturas, rodas literárias, atividades e exposição dos livros, entre outras.

As contribuições de Silva (1997), citado acima, deixam clara a importância do bibliotecário escolar para a sociedade. Sua presença é necessária para dar sentido à existência da biblioteca e organizar os materiais bibliográficos, bem como, salienta Lopes (2011, p. 225), “apresentar uma proposta de incentivo e valorização do livro como essência no processo de formação de leitores".

Sabe-se que, na atualidade, existem muitos livros online (e-book) disponíveis para 
leitura, porém, para que o espaço da biblioteca escolar não se torne obsoleto, temos que valorizar as várias literaturas excelentes doadas pelo PNBE (Programa Nacional Biblioteca da Escola) que estão disponíveis nas bibliotecas escolares.

O PNBE é composto pelos seguintes gêneros literários: obras clássicas da literatura universal; poema; conto, crônica, novela, teatro, texto da tradição popular; romance; memória, diário, biografia, relatos de experiências; livros de imagens e histórias em quadrinhos. (FNDE, 2016).

Toda criança, desde os primeiros anos de vida, possui uma grande fascinação por sons, figuras coloridas, histórias contadas ou lidas, canções ou cantigas. Logo que lhes são apresentados os primeiros livros, ainda que não saibam ler, os pequenos já se encantam com as ilustrações e querem tocar, pegar os livros e manuseá-los.

Esse encantamento fica ainda maior quando se deparam com os textos literários, as histórias encantadoras que cada autor explicita em suas obras. $\mathrm{Na}$ literatura fica claro que as crianças gostam das histórias e se encantam com as ilustrações.

Para Pinheiro (2017, p. 34), "As atividades de incentivo à leitura desenvolvem no leitor o gosto pela leitura e pelo livro, motivando-o a conhecer os diversos tipos de textos e escritas, buscando conhecer os diversos tipos de literatura." E diz ainda: "a leitura, seja ela literária ou não, traz benefícios no desenvolvimento cognitivo do indivíduo."

Embora existam muitas obras eletrônicas, há toda uma magia e encantamento no toque dos livros, que não podem ser substituídos. Isso não significa que essas obras eletrônicas não sejam importantes e que não devam ser incluídas no cotidiano da vida escolar do aluno.

Para que a biblioteca escolar seja um alicerce para a constituição de leitores deve ser um local repleto de comprometimento e de acesso a todos os leitores. Nesta linha de pensamento, Bicheri e Almeida Junior (2013, p. 42) mencionam que "É preciso que o bibliotecário conheça sua responsabilidade, e, nessa tarefa, atue deforma a contribuir para a formação de leitores."

Assim, passamos a entender a fundamental relevância do profissional bibliotecário, porque ele tem uma responsabilidade conjunta em formar leitores, apoiando a escola, a sociedade e lidando diretamente com as crianças, conduzindo-as para esse mundo encantador da leitura e contribuindo para possibilitar, para o futuro, bons leitores.

Segundo Pinheiro; Rodrigues (2014, p. 7), “os bibliotecários, por sua vez, precisam ter habilidades para a organização e técnicas criativas para motivar a leitura, tornando as atividades mais atraentes".

Mediar a leitura não é tarefa muito fácil, ou seja, é um grande desafio, especialmente com os adolescentes, e assim, não pode se esquecer que o papel dos pais é de grande contribuição na formação da criança leitora. Desde cedo devem buscar motivar a leitura, lendo para eles. Neste contexto, promover atividades envolvendo a família será de grande benefício na função educativa dos alunos.

Para Cademartori (2010, p. 1), diz que "a mediação do professor é decisiva na relação que a criança irá estabelecer com a literatura infantil", mas não é só o professor, o bibliotecário escolar também tem esse papel de interagir aluno com a literatura.

\section{BIBLIOTECA DA ESCOLA ESTA- DUAL PROFESSORA RENILDA SIL- VA MORAES}

A biblioteca faz parte da Escola Estadual Professora Renilda Silva Moraes, localizada na Rua Jacarandás, s/n - Coophalis, na cidade de Rondonópolis - MT. A Escola atualmente está com 846 alunos matriculados, destes 415 são crianças do $1^{\circ}$ ciclo - $1^{\mathrm{a}}$ fase ao $2^{\mathrm{o}}$ ciclo $-2^{\mathrm{a}}$ fase e, tem como missão formar pensadores críticos e responsáveis, de promover serviços de apoio ao ensino-aprendizagem aos membros da comunidade escolar, oferecendo-lhes a informação e disponibilizando serviços de igual modo a todos, independentemente de 
idade, etnias, religião, sexo, nacionalidade e estatuto profissional e social.

A biblioteca foi fundada por volta de 1998, e hoje possui um acervo com aproximadamente 6.200 mil obras, sendo que destas cerca de 500 obras são de literatura infantil e 4100 infanto-juvenil e adultos. Tem no quadro funcional três profissionais contratados pela Seduc Secretaria da Educação do Estado de Mato Grosso.
A organização do acervo é classificado pelo gênero, conforme Classificação Decimal Universal (CDU), e também pela notação de autor e título, ou seja, pelas três primeiras letras inicias do último sobrenome do primeiro autor; depois as três primeiras letras iniciais do título e, por último, mas não menos importante, uma tarja da cor correspondente a Tabela de Classificação em cores, conforme figura 1 , a seguir.

Figura 1 - Classificação pela CDU, notação de autor, título e classificação em cores

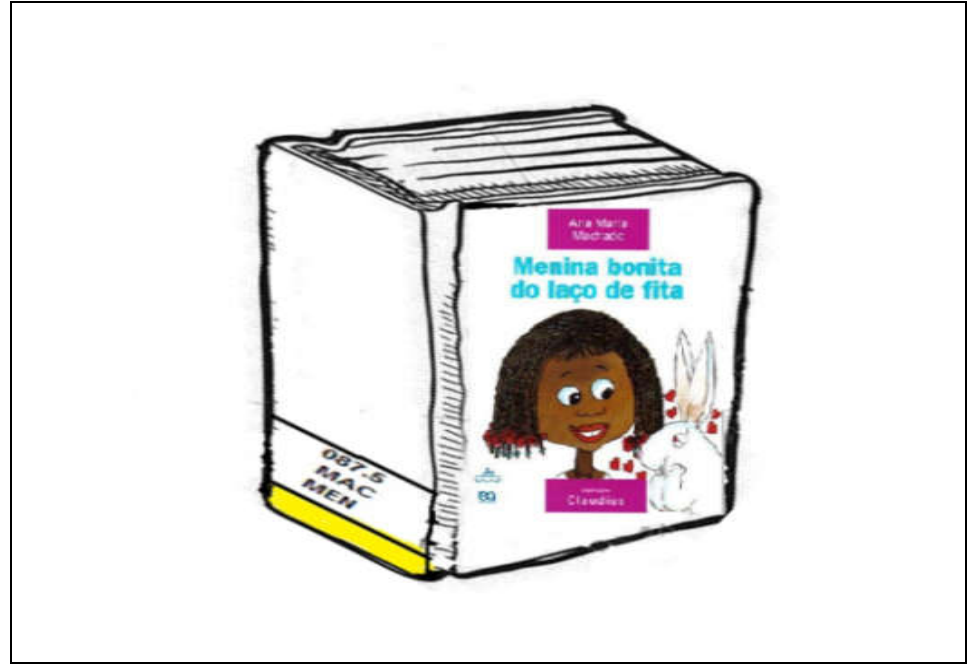

Fonte: Pinheiro e Rodrigues (2014).

A biblioteca tem como política de empréstimo a disponibilização de todos os materiais bibliográficos (livros e revistas), para consultas e empréstimos domiciliar. Os usuários são a clientela escolar e a comunidade que, de segunda-feira a sextafeira, nos dois períodos de funcionamento da escola (matutino - das $7 \mathrm{~h}$ às $11 \mathrm{~h}$; e vespertino - das $13 \mathrm{~h}$ às $17 \mathrm{~h}$ ), buscam por algum tipo de informação ou algum interesse de leitura.

Além disso, a biblioteca se envolve também com atendimento aos alunos nos trabalhos escolares fornecendo materiais para suas pesquisas e leitura; disponibiliza livros infantis para o Projeto de Leitura "Siga em sala de aula"; Seleção de livros de literaturas e gibis aos professores para realização de atividades de leitura extraclasse com os alunos e a participação em reuniões pedagógicas e contação de histórias, entre outros, conforme mencionado anteriormente.

A seguir, temos alguns exemplos importantes aplicados pela biblioteca no processo de mediação da leitura:

- Projeto de leitura - Carrinho da leitura;

- Projeto de leitura - Leitura ilustrada;

- Projeto de leitura - Hora da imaginação;

- Projeto de leitura - Recontando sua história.

Os três primeiros projetos são realizados juntamente com os professores em sala de aula.

A atividade "Recontando sua história" acontece sempre na hora da devolução das obras. As crianças contam o que entenderam das histórias lidas e, neste 
momento, estabelece-se um diálogo com as crianças sobre cada leitura. É estabelecido um cronograma com dias e horários aos professores para que cada turma faça a devolução das obras literárias.

Além destas atividades, segundo a bibliotecária responsável, são lidas as literaturas doadas pelo PNBE antes de irem para a estante. Também participa da escolha dos títulos doados pela comunidade e pelas aquisições que irão compor o acervo por compra realizada pela direção da Escola.

Todos esses cuidados são para evitar que a criança retire livros que não são próprios para sua idade. Além de interagir e participar com os alunos e com os professores, disponibilizando as informações e materiais necessários para o ensinoaprendizagem e colaborar no planejamento pedagógico da escola.

Portanto, ao ler algumas pesquisas mencionando que as bibliotecas escolares no Brasil são locais sem vida, constatou-se que a Biblioteca da Escola Estadual Professora Renilda Silva Moraes, através deste estudo, tem um diferencial, que já tinha sido constatado em outra pesquisa, conforme mencionam Pinheiro e Rodrigues (2014, p. 6),

[...] a bibliotecária vem favorecendo aos alunos uma realidade que dificilmente se encontra em outras Bibliotecas do país - acesso a biblioteca com prazer. Mas com um diferencial: a leitura é realizada, as retiradas de literaturas são constantes, a presença dos alunos é grandiosa na biblioteca, que mais parece uma "colmeia", ao redor dos livros.

\section{ANÁLISE DA PESQUISA E CONSIDERAÇÕES FINAIS}

Existem várias formas de mediar a leitura, como foi citada acima. As iniciativas desenvolvidas pela Biblioteca da Escola Estadual Professora Renilda Silva Moraes com as crianças são simples, mas estão proporcionando bons resultados. A experiência envolvendo a leitura na biblioteca nesta escola confirma a importância do bibliotecário como mediador de ações para o desenvolvimento de capacidades leitoras.

Os objetivos da pesquisa foram alcançados, o nível de compreensão das histórias foi de fácil entendimento e que todas as obras estudadas apresentam uma moral explícita ou implícita, demonstrando algumas mensagens de amor, amizade e respeito à natureza. Contatou-se também que a bibliotecária lê as literaturas infantis antes de disponibilizarem na estante, ou seja, a obra adquirida pela biblioteca sempre é lida pela bibliotecária na hora do tombamento. Essa pré-leitura ajuda o bibliotecário na hora do diálogo, pois fica conhecendo todas as histórias para poder sugerir ou conversar com os alunos.

Segundo a bibliotecária, "nunca interfiro na imaginação de cada depoimento sobre as leituras realizadas por estes leitores infantis, apenas realizamos um diálogo".

Uma das principais finalidades da literatura infantil é encantar a criança, na união do entretenimento e da instrução ao prazer da leitura, reunindo a beleza das imagens e das palavras, levando a criança a desenvolver as suas capacidades de emoção, admiração, compreensão do ser humano e do mundo, entendimento dos problemas alheios e dos seus próprios, enriquecendo principalmente as suas experiências escolares, cidadãs e pessoais. (LAJOLO; ZILBERMAN,1988).

Desta forma, a pesquisa mostra que é realizado a mediação literária com as crianças, sempre no momento da devolução das obras e que, segundo a bibliotecária, é o "momento do encantamento".

É preciso motivar, desde cedo, a leitura de textos literários para desenvolver o senso crítico de cada criança com a compreensão do significado dos textos. É importante que ela leve em conta as relações daquela obra com outras do mesmo ou de outros autores, estabelecendo desde cedo a intertextualidade entre os textos. Por exemplo, com a época em que foi escrita a obra, com a atualidade, propiciando a capacidade de ler, refletir, pensar, mas 
também sentir, emocionar-se, apurar a sensibilidade, sonhar e amar (AMORIN, 2010). Assim, poderá sempre relacionar tudo o que lê com o mundo que a cerca e compreender a diversidade de significados que o texto literário oferece.

$\mathrm{Na}$ biblioteca escolar, o bibliotecário tem participação especial nesse processo de escolha da obra para ampliar o acervo. Neste aspecto, a qualidade do acervo encontra-se condicionada a vários fatores, e um deles é a figura do bibliotecário, que pode fazer toda a diferença contornada pela criatividade, pelo empenho e pelo senso de responsabilidade social, contida nesse profissional.

Desta maneira, que Pinheiro e Rodrigues (2014) enfatizam que a presença do bibliotecário no processo pedagógico é imprescindível no auxilio efetivo do desenvolvimento educacional da escola através do auxiliar as leituras, as atividades culturais e sociais que proporcionarão oportunidades de ampliar conhecimentos aos estudantes.

Em suma, o papel do bibliotecário mediador se torna essencial quando age como agentes educadores em prol da criança leitora, pois se acredita que a leitura aumentará sua capacidade crítica e reflexiva que lhe permitirá atuar melhor na sociedade.

Nesta visão, Bicheri e Almeida Junior (2013, p. 43) aludem que:

$$
\begin{aligned}
& \text { Para que a biblioteca escolar possa } \\
& \text { cumprir com seu papel é } \\
& \text { necessário, além de espaço e } \\
& \text { acervo, de um bibliotecário } \\
& \text { competente e engajado na escola } \\
& \text { como um todo. Importa, e muito, a } \\
& \text { qualidade das atividades, as atitudes } \\
& \text { tomadas pelo bibliotecário, que } \\
& \text { deve ser competente, comunicativo, } \\
& \text { interessado e criativo. }
\end{aligned}
$$

Por fim, se todas as escolas tivessem professores e bibliotecários com habilidades para elaboração de projetos e técnicas criativas para motivar a leitura literária tornando as atividades mais atraentes, talvez, poderia existir um maior número de leitores.

Um sonho é que todo leitor infantil tenha à sua disposição uma biblioteca escolar e que toda biblioteca escolar tenha um bibliotecário leitor.

\title{
LITERARY READING FOR CHILDREN AND THE ROLE OF THE MEDIATOR LI- BRARY
}

\begin{abstract}
The research has as object of study the children's stories of the library of the 'Escola Estadual Professora Renilda Silva Moraes" of the city of Rondonópolis - MT. Thus, the objectives were to identify the moral of these stories; what message is left for the children and if the librarian reads the literature before putting it on the shelves. The sample included 100 works randomly selected on the shelf during the period from April to June 2015 and had two indicators for analysis: the level of understanding and the moral of the story, which allowed to point out which narratives are most suitable for elementary school children. At the end of this research, it was realized that as important as whether a child's work presents or not a "moral of history" is a reaffirmation of the idea that books are a good way to expand the cultural universe of future readers, opportunizing to come into contact with unknown and / or different situations. The results also show that giving children the opportunity to get to know a literary work can contribute to learning to enjoy reading. It is concluded in a synthesized way that the level of understanding of the stories was easy to understand and that all the works studied present an explicit or implicit morality, showing some messages of love, friendship and respect for nature. The librarian reads the works at the time of writing. Thus, reading and understanding children's literature are ways to love and travel in stories.
\end{abstract}

Keywords

Children's literature. Moral of the story. Literary reading. Librarian mediator. Artigo recebido em 29/06/2017 e aceito para publicação em 02/05/2018

REFERÊNCIAS

AMORIN, T. L. A leitura literária e a

formação do leitor. Webartigos. Disponível em: <https://www.webartigos.com/>.

Acesso em: 31 out. 2017. 
BICHERI, A. L. A. O.; ALMEIDA JUNIOR, O. F. Bibliotecário escolar: um mediador de leitura. Bibl. Esc, Ribeirão Preto, v. 2, n. 1, p. 41-54, 2013. Disponível em: $<$ http://www.revistas.usp.br/berev/issue/v iew/8114> . Acesso em: 20 mar. 2016.

BRASIL. Presidência da República. Lei N ${ }^{\circ}$ 12.244 de 24 de maio de 2010. Disponível em: $<$

http://www.planalto.gov.br/ccivel_03/_ato 2007-2010/2010/lei/112244.htm > Acesso em: 05 fev. 2016.

CADEMARTORI, L. Literatura infantil. 2010. Disponível em:

<http://ceale.fae.ufmg.br/app/webroot/glo ssarioceale/verbetes/literatura-infantil > Acesso em: 28 jan. 2016.

CAGNETI, S. S. Livro que te quero livre. Rio de Janeiro: Nórdica, 1996.

CALDIN, C. F. A função social da leitura da literatura infantil. Encontros Bibli: revista eletrônica de Biblioteconomia e Ciência da Informação, Florianópolis, 2003. $<$ https://periodicos.ufsc.br/index.php/eb/ article/view/1518-

2924.2003v8n15p47>.Acesso em: 18 dez. 2015.

CARVALHO, B. V. A literatura infantil : visão histórica e crítica. 6. ed. São Paulo: Global, 1989.

COELHO, N. N. Literatura infantil. São Paulo: Ed. Moderna, 2000.

Panorama histórico da literatura infantil/juvenil: das origens indo européias ao Brasil contemporâneo. 4 ed. Ática, 1991.

COLOMER, T. Andar entre livros: a leitura literária na escola. São Paulo: Global, 2007.

DURBAN ROCA, G. Biblioteca escolar hoje: recurso estratégico para a escola. Porto Alegre: Penso, 2012. eBook. Disponível em:
$<$ https://books.google.com.br/books?id=a $\mathrm{XCwWq3ATT4C \& pg=PA4 \& hl=pt-}$

$\mathrm{BR} \&$ source $=\mathrm{gbs}$ _selected_pages\&cad $=2 \# \mathrm{~V}$ $=$ onepage $\& \mathrm{q} \& \mathrm{f}=$ false $>$. Acesso em: $7 \mathrm{fev}$. 2016.

FNDE. Programas de bibliotecas da escola. 2015. Disponível em: $<$ http://www.fnde.gov.br/programas/bibli oteca-da-escola/biblioteca-da-escolaapresentacao> . Acesso em: 16 nov. 2015.

\section{IFLA/UNESCO. MANIFESTO} IFLA/UNESCO para biblioteca escolar. Trad. por MACEDO, Neusa Dias de.

Disponível em:

<http://www.ifla.org/VII/s11/pubs/portu guese-brazil.pdf>. Acesso em: 26.dez.2015.

LAJOLO, M. Do mundo da leitura para a leitura do mundo. 6. ed. São Paulo: Editora Ática, 2001.

\section{.; ZILBERMAN, R. Literatura in-}

fantil brasileira: história

\&histórias. 4. ed. São Paulo: Ática, 1988.

MIRANDA, A. L. Moral da história. Nova Friburgo, RJ: Girlam Editores, 2015. Disponível em:

$<$ https://books.google.com.br/books?id $=\mathrm{O}$ HY6CwAAQBAJ\&pg=PT4\&dq=moraldahi st $\%$ C $3 \%$ B 3 ria\&hl $=$ pt-

BR\&sa $=\mathrm{X} \& v e d=0 \mathrm{ahUKEwjnior} 32 \mathrm{MjLAhV}$ Fx5AKHeYODJgQ6AEIHjAA\#v=onepage $\& q=$ moraldahist $\% \mathrm{C} 3 \% \mathrm{~B} 3$ ria\& $\mathrm{f}=$ false $>$ Acesso em: 17 mar. 2016.

MORIGI, J. V.; SOUTO, L. R.. Entre o passado e o presente: as visões de biblioteca no mundo contemporâneo. Revista ACB: Biblioteconomia em Santa Catarina, v.10, n.2, p.189-206, jan./dez. 2005. Disponível em:

$<$ http:www.brapciufpr.br/download.php?d= 11138... >. Acesso em: 16. jan. 2016.

ORLANDI, E. P. Discurso e texto: formação e circulação dos sentidos. Campinas, SP: Pontes, 2001. 
PIAGET, J. O juízo moral na criança. Tradução Elzon L. 2. ed. São Paulo:

Summus, 1994.

PINHEIRO, M. I. S. Biblioteca escolar na visão das crianças do ensino fundamental.

Revista ACB: Biblioteconomia em Santa Catarina, Florianópolis, v. 22, n. 1, p. 31-37, dez./mar., 2017. Disponível em:

$<$ https://revista.acbsc.org.br/racb/article/v iew/1199/pdf> . Acesso em: 03 abr. 2017.

PINHEIRO, M. I. S.; RODRIGUES, L. R.

Q. Bibliotecário nas escolas: um bem que faz bem ao futuro das crianças. Revista ACB: Biblioteconomia em Santa Catarina, Floria- nópolis, v. 19, n. 2, p. 260-271, jul./dez., 2014. Disponível em:

$<$ http://revista.acbsc.org.br/racb/article/vi ew/968/pdf_104>.

Acesso em: 20 dez. 2015.

SANTOS, L. W. Leitura literária na escola. Interdisciplinar, Ano IX, v.21, jul./dez. 2014. Disponível em:

$<$ https://seer.ufs.br/index.php/interdiscipli nar/article/viewFile/2580/2205>. Acesso em: 10 jun. 2016.

SILVA, E. T. Leitura e realidade brasileira. Porto Alegre: Mercado aberto, 1997. 